\title{
ARTÍCULOS
}

\section{EL PCE EN LA LUPA DE LA BRIGADA POLÍTICO SOCIAL. LOS COMUNISTAS EN LOS BOLETINES POLICIALES (1938-1975)}

The PCE in the magnifying glass of the Political Social Brigade.

The communists in the police bulletins (1938-1975)

Pablo Alcántara Pérez

Universidad Autónoma de Madrid pablo.alcantara@estudiante.uam.es

Orcid: 0000-0002-1656-261X

Recibido: 20-07-2020- Aceptado: 29-09-2020

Cómocitaresteartículo/Citation:

Pablo Alcántara Pérez "El PCE en la lupa de la brigada político social. Los comunistas en los boletines policiales (1938-1975)".Hispania Nova, 19 (2021): 291 a 324.

DOI: https://doi.org/10.20318/hn.2021.5883

Copyright:CHISPANIA NOVAes una revista debidamente registrada, con ISSN 1138-7319 y Depósito Legal M 9472-1998. Los textos publicados están -si no se indica lo contrario- bajo una licencia Reconocimiento-Sin obras derivadas 3.0 España de Creative Commons. Puede copiarlos, distribuirlos y comunicarlos públicamente siempre que cite su autor y la revista y la institución que los publica y no haga con ellos obras derivadas. La licencia completa se puede consultar en: http://creativecommons.org/licenses/by-nd/3.0/es/deed.es

Resumen: Los comunistas, y concretamente el PCE, siempre fueron uno de los principales objetivos por parte de las fuerzas de orden público franquistas. Tanto por convertirse a lo largo de las décadas en la principal fuerza de oposición al régimen a través del movimiento obrero, estudiantil y después en otros sectores sociales como los intelectuales, la cultura o las profesiones liberales, como por el anticomunismo intrínseco del régimen. Por ello, la policía, y concretamente la Brigada Político Social, le dedico una especial atención a la hora de realizar sus análisis sobre la situación interna del país. En un primer momento, a través de los conocidos Boletines AntiMarxistas, realizados por Eduardo Comín Colomer, policía y escritor propagandista, y que tuvieron una duración de 1938 hasta 1945, y que tienen un contenido más ideológico que práctico. A partir de 1946, se empiezan a editar los Boletines de Investigación Social, que contienen información más precisa sobre las detenciones, las personas a las que detienen, la propaganda que incautaban, etc. La idea de este artículo sería hacer un análisis comparado de cómo va cambiando la visión sobre los comunistas a lo largo de la dictadura por parte de la BPS, según sus intereses, prácticas policiales, a través de estas informes, una de las principales fuentes policiales.

Palabras clave: Boletines, Anticomunismo, Brigada Político-Social, Investigación, Antifranquismo. 
Abstract: The communists, and specifically the PCE, have always been one of the main objectives of the Francoist public order forces. Both for becoming, over the decades, the main force of opposition to the regime through the labor, student movement and later in other social sectors such as intellectuals, culture or the liberal professions, and for the intrinsic anti-communism of the regime. For this reason, the police, and specifically the Political Social Brigade, pay special attention to it when carrying out their analysis of the country's internal situation. At first, through the well-known Anti-Marxist Bulletins, carried out by Eduardo Comín Colomer, police and propagandist writer, and which lasted from
1938 to 1945 , and which have a more ideological than practical content. Starting in 1946, the Social Investigation Bulletins began to be published, which contain more precise information about the arrests, the people they arrest, the propaganda they seized, etc. The idea of this article would be to make a comparative analysis of how the vision of communists throughout the dictatorship by the BPS is changing, according to their interests, police practices, through these reports, one of the main police sources .

Keywords: Bulletins, Anti-Communism, Political-Social Brigade, Research, AntiFrancoism.

\section{INTRODUCCIÓN: LA EVOLUCIÓN DE LOS BOLETINES POLICIALES FRANQUISTAS. DE LOS BOLETINES DE INFORMACIÓN ANTI-MARXISTA A LOS BOLETINES DE INVESTIGACIÓN SOCIAL}

Durante los años de la dictadura franquista, los miembros de la Brigada Político Social (BPS) se prepararon ideológicamente para hacer frente a la oposición antifranquista. Crearon boletines de información primero, como forma de instrucción sobre el movimiento obrero, republicano, de izquierdas, en base a la propaganda del régimen y después, los utilizaron para anunciar las detenciones que realizaban en el país y analizar la forma de actuar frente al movimiento obrero o estudiantil. También hubo policías que escribieron libros sobre diferentes temas relacionados con el comunismo, anarquismo, masonería, y de cómo hacer frente a la "subversión".

El 20 de abril de 1937, Franco informó a los mandos de los distintos ejércitos de la existencia de un gabinete destinado a recoger e investigar la documentación que incautaban a los republicanos, para contrarrestar "la propaganda comunista" en España. Se llamaba Oficina de Investigación y Propaganda Anticomunista (OIPA). Tras la caída de Bilbao en julio de 1937, se convirtió en un instrumento encargado de recopilar todo el material posible para organizar la represión política de la posguerra. Se creó para ello, el 27 de mayo de 1938, el Servicio para la Recuperación de Documentos, dirigido por Marcelino de Ulibarri, secretario particular y consejero de Franco. Esta oficina se encargaba de, cuando los sublevados entraban en una ciudad, realizar registros en los 
locales de las organizaciones que aglutinaban el Frente Popular y sindicatos y conseguir toda la información posible que pudiera permitir enjuiciar a todos los que se habían opuesta al Golpe de Estado. Con ello, se creó en Salamanca un archivo documental con más de 3000000 de fichas personales ${ }^{1}$.

El trabajo de "archivero" y "documentalista" lo realizaría el policía-escritor Eduardo Serafín Comín Colomer, que le servirá para recopilar documentación y escribir libros haciendo apología del régimen, criticando las ideologías de las organizaciones del Frente Popular. El expediente policial de Comín Colomer enumera sus campos de conocimiento: “judaísmo, masonería, espiritismo, marxismo, anarquismo, especializándose durante sus servicios en la delegación de recuperación de documentos"2. Comín Colomer utilizó toda la documentación que encontró de las organizaciones republicanas, para crear los "Boletines de Información Anti-Marxistas (BIA)".Estos boletines eran de consulta exclusivamente para el Cuerpo General de Policía $^{3}$.

Se realizaron un total de 40 boletines entre 1939 y 1945. Iban de 9 a 29 páginas. Primero, hasta enero hasta febrero de 1939 eran bisemanales.En 1941 fueron mensuales y de enero de 1942 hasta octubre de 1945 fueron bimensuales. En ellos se trataron diferentes temas: 18 boletines sobre los comunistas y el PCE, tanto a nivel internacional como nacional, once hablan sobre masonería, dos sobre el socialismo y el PSOE, tres sobre la CNT y anarcosindicalismo, siete en los que se hablan de los judíos, uno sobre la Asociación Internacional de Trabajadores. En ellos, Comín Colomer relacionaba a la mayoría de organizaciones con la masonería, el judaísmo o el comunismo, apuntando en los BIA la visión de la "conjunción masónica” que tenía el régimen sobre la oposición ${ }^{4}$.

\footnotetext{
${ }^{1}$ Gutmaro Góme y Jorge Marco, La obra del miedo. Violencia y sociedad en la España franquista (19361950), (Madrid: editorial Península, 2011, pp. 159-163 y Gutmaro, Gómez Bravo Geografía Humana de la represión franquista. Del golpe a la guerra de ocupación. 1936-1941. (Madrid: ed. Cátedra, 2017), pp. 117-118.

2 DGS, Inspeccion General de Personal, “Expediente personal Eduardo Comín Colomer”, n70256, AGMI, p. 177.

${ }^{3}$ Julio Rodríguez Puertolas, Literatura fascista española, (Madrid: Ed. Akal, 1986), p. 737.

${ }^{4}$ Estos boletines de información anti marxistra los he encontrado en el Centro Documental de la Memoria Histórica en Salamanca y en el Archivo Histórico Nacional. Pedro Víctor Fernández Fernández "El Boletín de información anti-marxista: un ejemplo de espíritu antimasónica del franquismo" en José Antonio Ferrer (coord.) Masonería, revolución y reacción, (Ed. Diputación Provincial de Alicante, 1990), vol. 1, p. 44.
} 
Tras 1945, los boletines anti-marxistas desaparecieron, dando paso a los Boletines de Investigación Social (BIS), que ya no se centraron tanto en las cuestiones teóricas o históricas de las diferentes organizaciones políticas, sino que serán boletines más sobre la actuación policial y sobre cómo proceder ante la "subversión".Ya tenían su justificación teórica en los BIA. Ahora necesitaban llevar todos esos supuestos conocimientos a la práctica.

La idea de este artículo es analizar estos boletines de investigación policial, desde el año 1938 hasta 1975, que tratan sobre el PCE.Ver sus análisis políticos y policiales sobre los comunistas españoles. Los avances en su forma de ver y de analizarlos. Ver las diferencias, en diversas etapas, de estos boletines policiales, que era uno de los principales órganos de expresión de los miembros de la policía política franquista, ante uno de sus principales "enemigos". Durante años no ha habido una investigación serie sobre la Brigada Político Social. Estos boletines constituyen una fuente fundamental para el estudio de esta política política ${ }^{5}$.

\section{EL PCE EN LOS BOLETINES DE INFORMACIÓN ANTI-MARXISTA}

(1938-1945)

Tras la Guerra Civil, a pesar de la represión, la miseria, y de que la organización se viera muy mermada, el PCE era el partido mejor preparado para la clandestinidad, ya que durante la contienda había alcanzado un gran poder de organización, con una disciplina férrea por parte de la militancia. Además era el único partido que contaba con una organización implantada en todo el país, tanto territorialmente como profesionalmente. También jugó un papel la ayuda de la Internacional Comunista. ${ }^{6}$.

\footnotetext{
5 Juan José del Águila Torres El Tribunal de Orden Público 1963-1977, trece años de represión política (1963-1977), Tesis Doctoral, (Universidad de Sevilla, 1997), pp. 106-107.

${ }^{6}$ Edualdo Casanova Surroca, El partido comunista de España (1920-1991), Zaragoza, ed. Saberes inútiles, 2018, pp. 203-206; Enrique González De Andrés, "La naturaleza política de la dictadura franquista según el PCE y sus efectos en los inicios de la Transición Española" en Alejandra Ibarra Aguirregabiria (coord.) No es país para jóvenes, Asociación Histórica Contemporánea. Actas Encuentro Jóvenes Investigadores, 2012; pp. 1-3; Fernando Hernández Sánchez, Los años de plomo: la reconstrucción del PCE en el primer franquismo (1939-1953), (Barcelona: ed. Crítica, 2015) 89-92 y
} 
Durante los primeros años 40, los comunistas basaron su lucha, sobre todo, en el movimiento guerrillero, en la lucha armada en los montes, donde estaban los conocidos como "huidos". El 22 de junio de 1941, con la invasión alemana de la Unión Soviética, el PCE creó la Unión Nacional Española (UNE), que en sus inicios participó en la Resistencia francesa contra los nazis y que pretendía llevar a cabo un desembarco militar en España, siendo comandados por Jesús Monzón Reparaz. Se crearon diferentes guerrillas autóctonas por toda la geografía española, lo que en el diagnóstico del PCE suponía que había un caldo de cultivo contra la dictadura.En septiembre de 1943 se constituyó la Junta Suprema de la UNE en Madrid. Tras el fracaso de la conocida como “Operación Reconquista”, en la que 3000 hombres armados se internaron en España por el Valle de Arán, la UNE fue desmantelada al año siguiente y Jesús Monzón depurado por la dirección de sus cargos ${ }^{7}$.

El franquismo justificó el Golpe de Estado del 18 de julio y la Guerra Civil como un enfrentamiento de España "contra el peligro comunista". Fue utilizado como chivo expiatorio en todo tipo de conflictos. Según el propio Franco, el comunismo integraba tres aspectos fundamentales: la idea, la acción clandestina y el Ejército Soviético. Era el "mal" por su "carácter satánico", un "virus corrosivo" del que "España estaba vacunada". Todas estas ideas del dictador fueron transmitidas al Estado que dirigía, incluidos estamentos como la policía política ${ }^{8}$.

Esta visión anticomunista será trasladada a los Boletines policiales, ya desde sus inicios. De hecho, en un primer momento, los conocidos como Boletines de Información Anti-Marxista (BIA), los comunistas, tanto su organización internacional como nacional, eran muy importantes en sus análisis. De los 45 boletines que se publicaron entre 1938 y 1945, 18 estaban dedicados al PCE, la Internacional Comunista, la GPU (la policía política soviética) o las diferentes organizaciones comunistas dentro de nuestro país, en el exilio o extranjeras.

Gregorio Morán, Miseria, grandeza y agonía del PCE (1939-1985), (Madrid: ed. Akal, 2018 reed. 1986) pp. 55-57.

${ }^{7}$ Benito Díaz Díaz, "Tiempos de violencia desigual: guerrilleros contra Franco (1939-1952)” Vínculos de Historia, №. 5, 2016, pp. 61-71; Fernando, Hernández Sánchez, La frontera salvaje: un frente de sombrio del combate contra Franco, (Barcelona: ed. Pasado y Presente, 2018), pp. 19-29; Ramón, García Piñeiro, Luchadores del ocaso (Oviedo: KRK, 2015), pp. 279-288 y Jorge Marco, Guerrilleros y vecinos en armas. Identidades y culturas de la resistencia antifranquista. (Granada: ed. Comares, 2012), pp. 55-56.

${ }^{8}$ Miguel Ángel Giménez Martínez, "El corpus ideológico del franquismo: principios originarios y elementos de renovación" Estudios Internacionales Instituto de Estudios Internacionales - Universidad de Chile, ${ }^{\circ} 180,2015$, pp. 23-24. 
En los diversos informes sobre las organizaciones comunistas a nivel mundial (a los que dedicó sus dos primeros boletines y un total de once de los 18 documentos sobre los comunistas) Comín Colomer expresó que la URSS "tiene intenciones de llevar a cabo la revolución comunista mundial". Que la III Internacional tenía un "plan de guía revolucionario del proletariado mundial" y consideraba a esta organización como un “super-estado dictatorial” cuyo plan era "la República Soviética Universal".Que a través de sus organizaciones (el Socorro Rojo Internacional o los Amigos de la Unión Soviética) el PCE y el gobierno republicano recibían "enorme cantidades de dinero." Para referirse a esta cuestión, el autor habla del "Oro Ruso", otro mito de la propaganda franquista como la cuestión del "Oro de Moscú" que el gobierno del Frente Popular supuestamente había entregado a la URSS a cambio de armas ${ }^{9}$.

Que los Frentes Populares formados en España o Francia tenían como objetivo ampliar "el campo de acción comunistoide". Considera organizaciones como el Socorro Rojo se encargaban de "recaudar fondos destinados a mantener en tensión el ideal de la lucha de clases".Al autor le interesaba mucho el papel de la policía política soviética, la GPU, a nivel internacional, a la que dedicará sus últimos boletines. Vinculaba a esta policía con el "terror rojo" durante la Guerra Civil y la enlazaba a una serie de asesinatos que se dieron en nuestro país, como el rapto de Erwin Wolf, secretario de Trotsky, el 13 de octubre de 1937, y el asesinato del socialista Bob Mill y un nieto de Francisco Ferrer. Según el autor, España “era presa codiciada por Moscú” y por ello consideraba que "los ejes, dirigentes, checas y vengadores han sido comunistas y más concretamente, especialistas revolucionarios preparados debidamente por Moscú", refiriéndose a los dirigentes del Ejército Republicano durante la Guerra Civil ${ }^{10}$.

Esta obsesión por ligar toda actividad del PCE en los años de su fundación, la II República, la Guerra Civil y la posguerra con la Komintern se verá reflejada incluso en el título del primer documento (el cuarto boletín, de noviembre de 1938) donde se trata la organización española a la que se la nombra como "sección española de la Internacional Comunista".

\footnotetext{
${ }^{9}$ DGS, Boletines de Información Anti-marxista, Internacional Comunista", 20/10/1938, n 1 "CDMH, pp.1-3; DGS, Boletines de Información Anti-Marxista, "El Ekki o Comité Ejecutivo de la Internacional Comunista", 31/10/1938, CDMH, pp. 13-14

${ }^{10}$ DGS, Boletines de Información Anti-Marxista, "Socorro Rojo Internacional", CDMH, 15/12/1938, nº pp. 70-87; DGS, Boletines de Información Anti-Marxista, "La Policía Rusa en el mundo", 31/01/1939, nº CDMH pp. 134-136; DGS, Boletines de Información Anti-Marxista, "La policía soviética", noviembre-diciembre 1943, CDMH, pp. 4-7.
} 
En este primer boletín que habla del PCE, analizó la historia de la organización, desde sus inicios, a los que vincula con el nacimiento de la Komintern, hasta la Guerra Civil. No sólo entrelazaba los primeros momentos de los comunistas con los rusos, sino incluso con la masonería (señala que algunos de sus primeros dirigentes, como Daniel Anguiano Mangado, eran “masones”). Según el autor, los primeros secretarios generales del partido, como Bullejos, "recibían órdenes directas de la Komintern”. Durante los años republicanos, la organización se expandió por Andalucía, Castilla, Asturias y Vizcaya gracias al famoso "oro ruso", declara Comín Colomer. Recalcó como "soviéticas" o de "sangrienta persecución" medidas como la reforma agraria o el laicismo del primer gobierno republicano-socialista ${ }^{11}$.

Según datos del autor, en julio de 1936, antes de empezar la guerra, el PCE tenía 280000 afiliados, cuando al principio de la República eran 800. A continuación realizó una descripción detallada de como se organizaban los comunistas, desde su cúpula a través del Comité Central, pasando por sus diferentes secciones (sindical, agraria, trabajo de las mujeres, trabajo de las mujeres, agit-prop, finanzas, masas), después los comités provinciales, comarcales, de radio y las células, como el esquema que se seguía en los demás partidos comunistas del mundo, con arreglo de la Komintern. Dentro del boletín, aparece un esquema dibujado sobre dicha estructura ${ }^{12}$.

No será hasta el boletín de febrero-marzo de 1942, el número 8, de la segunda etapa de los Boletines Anti-Marxista, cuando volvió a analizar al PCE. En esta ocasión era para hablar de la actividad de la organización tras la victoria franquista en la Guerra Civil. En este boletín, se refiere a la agonía de los comunistas en España y a nivel mundial (en esos momentos se estaba librando la Segunda Guerra Mundial y Alemania estaba invadiendo la URSS) como “el espectáculo más grandioso que puede presentar la Humanidad". En esa "fiesta", España, según Colomer, había marcado la ruta a seguir con la derrota republicana frente a los ejércitos de Franco en la llamada por él y los propagandistas franquistas como "guerra de liberación"13.

\footnotetext{
${ }^{11}$ DGS, Boletines de Información Anti-Marxista, , "El Partido Comunista Español o la Sección Española de la Internacional Comunista", 20/11/1938, n4 CDMH, pp. 33-34

12 Ibídem. pp. 35-50.

${ }^{13}$ DGS Boletines de Información Anti-Marxista, "El Partido Comunista Español después del $1^{\circ}$ de abril de 1939”, febrero-marzo 1942, segunda época, n8, CDMH, pp. 5-6.
} 
Sin embargo "el monstruo" comunista seguía vivo, según el autor, en la "subversión, agitación y propaganda clandestina". Analizó como desde el primer día desde el final de la guerra, los comunistas se reorganizaron.Como estaban saliendo de las cárceles, "por benevolencia de Franco", estaban reconstruyendo la organización, utilizando su léxico "altisonante" de lucha contra los fascistas y explotadores. Examinó también las posturas que tenían los comunistas españoles sobre la Segunda Guerra Mundial en esos momentos, y los virajes ideológicos dependiendo de las actuaciones de la URSS en el conflicto, calificándola primero de "segunda guerra imperialista" cuando Alemania atacó a Inglaterra o Francia y después de "agresión nazi contra la pacífica Rusia" cuando los nazis comienzan la guerra en el frente oriental contra la URSS y se lanza el frente mundial de la humanidad antifascista ${ }^{14}$.

A continuación, estudió la línea política del Partido en el interior, de cómo mientras las demás organizaciones republicanas se replegaban en el exilio, los comunistas pretendían seguir su actividad clandestina. Comín describió como supuestamente los líderes comunistas se llevaron dinero de España al extranjero para llevar una "vida principesca", mientras en el interior se sigue reconstruyendo el Partido. Una de las formas de reconstruirlo era mediante la creación de la "Unión Nacional", una especie de nuevo Frente Popular, mediante la lucha guerrillera, para instaurar la "República Soviética, el fin de todos los comunistas", según el autor. En dicha organización querían aglutinar a todos los "descontentos con la situación actual” es decir, con el régimen franquista, aunque fueron católicos, de derechas, burgueses, y para ello renunciaban "al régimen soviético" y presentaban un programa de mínimos, que consistía en independencia y soberanía para España, libertad de los presos, lucha contra las potencias del Eje, protección de la mujer y la infancia, restablecimiento del Estatuto de Cataluña y País Vasco y desmilitarización de la juventud ${ }^{15}$.

Después, Comín Colomer analizó la organización comunista en el exilio y en el interior. Da nombres de algunos de los miembros del Comité Central. Además, Comín Colomer dejó escritos en el boletín las reglas de conducta de los militantes comunistas en los periodos de clandestinidad, su jerga, que el autor iguala a la de "los ladrones del mundo criminal", sobre sus cotizaciones, sus servicios de información, Incluso recoge

\footnotetext{
${ }^{14}$ Ibidem. pp.7-13.

${ }^{15}$ Ibídem. pp. 14-20.
} 
en su informe los debates entre los del interior y el exilio por ver quién debía realizar la propaganda. En este documento reflejó también la incertidumbre que los dirigentes de la organización tenían a las detenciones de la policía política y que se debía mantener todo tipo de precauciones para conseguir evitar el mayor número detenciones posibles. ${ }^{16}$.

El siguiente boletín, de abril y mayo de 1942, siguió analizando la actuación del PCE en la clandestinidad. El policía-escritor resaltó que a pesar de las detenciones realizadas, los grupos de comunistas que había desperdigados, habían conseguido formar "un aparato bastante eficiente". Le impresionaba como habían conseguido establecer contactos, enlaces de correspondencia, de mandar paquetes y giros al extranjero. Esta información que daba el autor se contradice con lo anterior expuesto de la rápida reorganización comunista tras la derrota en la Guerra Civil. Según el propio Comín, los comunistas estaban preparando a sus militantes para, si España entraba en guerra contra las potencias aliadas, estos se pasaran a dicho bando y lucharan contra Franco $^{17}$.

Interesante y novedoso en este boletín es cuando habla de la organización comunista en las cárceles, "lugares de marcada predilección para la propaganda comunista" y donde se dieron los primeros pasos para reorganizar el Partido y seguir con la actividad tras salir al exterior. Donde se captaba a nuevos militantes y se recuperaba a los antiguos compañeros. Según el autor, el fin del objetivo de conseguir nuevos compañeros era obtener mayores fondos para la organización. Recalca que la actividad de la organización comunista en las cárceles "ha sido muy reducida". Señala que tenía actividad en cinco cárceles madrileñas: Porlier, Ventas, Yeserías, Santa Rita y Comendadoras. Conocía hasta el fichero que hacían los jefes de las células en las cárceles para mandar al exilio, sobre la situación dentro, la moral de los compañeros, los casos jurídicos que había, la situación socio-política del país ${ }^{18}$.

Muchas de estas informaciones que daba Comín Colomer, como policía y escritor propagandista del régimen franquista, se han ido rebatiendo en investigaciones posteriores en los últimos años. Aunque sí que es verdad que la Internacional Comunista tuvo su influencia en el nacimiento de organizaciones comunistas en nuestro país y

\footnotetext{
${ }^{16}$ Ibidem. pp. 23-34.

${ }^{17}$ DGS, Boletín de Información Anti-Marxista, "El Partido Comunista Español después del $1^{\circ}$ de abril de 1939”, abril-mayo 1942, segunda época, nº, CDMH, pp. 4-10

${ }^{18}$ Ibídem. pp. 12-17.
} 
ayudó en su impulso y orientación inicial, incluso con financiación, también hubo ciertas diferencias entre la Komintern y la dirección del PCE. Por ejemplo, en los años republicanos, el PCE pasó periodos de clandestinidad, semilegalidad y legalidad. Pasaron de criticar "la república burguesa" a la constitución del Frente Popular con organizaciones republicanas en 1935, bajo las directrices de la Internacional Comunista. Sin embargo, algunos de sus líderes, como Bullejos, fueron destituidos por no seguir la política de la Komintern. Sin embargo, a pesar de estas represalias, el PCE consiguió tener una actividad legal y aumentar su número de militantes, pasando de 3000 militantes en mayo de 1931 a los 83967 en torno a julio de $1936^{19}$.

Sobre las relaciones entre el PCE y la Internacional Comunista o la GPU durante la Guerra Civil, ha habido unos cuantos debates dentro de la historiografía en las últimas décadas. Según los investigadores Antonio Elorza y Marta Bizcarrondo, el PCE era una parte de la Internacional Comunista, formando su sección española y siguiendo sus directrices. Un comunista argentino, Víctor Codovilla, estuvo entre 1932 y 1937 siendo agregado de la Komintern en nuestro país para asesorar a la organización comunista española. Para el historiador Fernando Hernández Sánchez, sin embargo, aunque el PCE pertenecía efectivamente a la Internacional, los tempos y la dinámica propia de la Guerra Civil, hizo que en muchas ocasiones la estrategia de los comunistas españoles no coincidiera con la de la Komintern, como por ejemplo, en la crisis ministerial que supuso la salida de Indalecio Prieto en abril de $1938^{20}$.

El historiador José María Faraldo, que investigó en los archivos rusos de la Internacional Comunista y de la policía soviética, dice que estos miembros de la policía secreta estuvieron en España durante la Guerra Civil y la posguerra. Participaron tres tipos distintos de policía en territorio español: la sección para el Comisariado para Asuntos Internos (NKVD), el Servicio de Inteligencia Militar (GRU) y la inteligencia de la Internacional Comunista. Sin embargo, no fueron los creadores de las "chekas" de las que hablaba la propaganda franquista, ya que en España, como ha demostrado el investigador Fernando Jiménez Herrera, estas supuestas “chekas” eran comités creados

\footnotetext{
19 Edualdo Casanova, El Partido..... op.cit. pp. 96-97 y 110-115 y Fernando Hernández Sánchez,"El Partido Comunista de España en la Segunda República" Bulletin d'Histoire Contemporaine de l'Espagne https://journals.openedition.org/bhce/684, pp. 86-91 y Fernando Hernández Sánchez, El PCE en la Guerra Civil, Tesis Doctoral, (Universidad Autónoma de Madrid, 2010), pp. 58-64.

20 Antonio Elorza y Marta Bizcarrondo, Queridos Camaradas. La Internacional Comunista y España (1931-1939), (Barcelona: ed. Planeta, 1999), pp. 444-445 y Fernando Hernández Sánchez, Guerra o revolución. El partido comunista en la Guerra Civil. (Barcelona: ed. Crítica), 2010, pp. 550-551.
} 
por ateneos libertarios, casas del pueblo, organizaciones comunistas, que fueron creadas para agrupar a las organizaciones republicanas tras el Golpe de Estado. Pero en ningún caso fueron diseñadas por la $\mathrm{GPU}^{21}$. A Stalin no le interesaba crear una República Soviética en España iniciando una revolución, sino mantener la república burguesa. La URSS no controló a la República, aunque sí tuvo ascendencia sobre ella. Ni tampoco les interesaba crear una policía soviética, aunque la GPU si participó en el entrenamiento de los servicios de seguridad de la República. Lo que más les interesaba a los servicios secretos rusos era contener la amenaza de los trotkistas, haciendo desaparecer al dirigente del POUM, Andreu Nin. Sin embargo, a partir de noviembre de 1937, España no interesaba en la política exterior soviética ${ }^{22}$.

Estas relaciones entre tira y afloja entre el PCE, la Internacional Comunista y los dirigentes soviéticos se vieron reflejados también durante la posguerra. Al finalizar el conflicto bélico español, muchos dirigentes comunistas marcharon a la URSS, como Dolores Ibárruri (que se convertiría en la secretaria general del PCE), Líster, etc etc. Muchos de sus cuadros militares se encuadrarían en el Ejército Rojo. Además la Komintern dio fondos a la organización comunista española ${ }^{23}$. Sin embargo, ciertos aspectos de la URSS y del devenir en la Segunda Guerra Mundial produjeron debates en el seno de la organización y hasta expulsiones, sobre todo, entre sus militantes y cuadros medios en el interior.

Por ejemplo la firma del pacto germano-soviético en agosto de 1939, produjo un shock dentro de las filas comunistas, aunque sus dirigentes se alinearon a defender el pacto. En el interior, en Madrid, en las cárceles hubo debates sobre la cuestión y aunque algunos defendían el pacto porque "el Partido Nazi luchaba contra el imperialismo anglo-francés", sin embargo a algunos les costó asimilarlo, aunque al final lo hicieron por "una plena confianza en la URSS" como relató en sus memorias Melquíades Rodríguez Chaos, preso comunista en dicha cárcel. Sin embargo, en el PSUC, las discrepancias a esta cuestión llevaron a la expulsión de varios dirigentes del partido y de

\footnotetext{
${ }^{21}$ Fernando Jiménez Herrera “¿Hubo checas en el Madrid de la guerra civil? estudio comparado de la policía política soviética y los comités revolucionarios españoles (Verano-otoño 1936)" Hispania Nova, n 17 (2019), pp. 74-76.

${ }^{22}$ José María Faraldo, Las redes de terror. Las policías secretas comunistas y su legado. (Madrid: Galaxia Gutenberg, 2018, pp. 138-141.

23 Edualdo Casanova, El Partido Comunista......op.cit, pp. 205-208 y Gregorio Morán, Miseria, grandeza ...op.cit., (Madrid: ed. Akal, 2018 re. 1986), pp. 40-42.
} 
la rama catalana de la UGT, que se encontraban en Méjico. Durante estos agitados días, los dirigentes de la Internacional Comunista (Dimitrov entre ellos) mantuvieron discusiones con los dirigente del PCE sobre la estrategia a seguir en España. Los jefes de la Komintern pedían a los comunistas españoles que abandonaran la lucha armada y penetraran en las organizaciones de la dictadura. Sin embargo, en un primero momento, esta estrategia no se llevo a cabo por el PCE, optando por las guerrillas, hasta finales de los años $40^{24}$.

\section{EL PCE EN LOS PRIMEROS BOLETINES DE INVESTIGACIÓN} SOCIAL (1946-1956)

"Dentro de las luchas extremistas, en ningún sector se produjeron acontecimientos con el método y perseverancia que llegó a caracterizar que llegó lo producido por los comunistas, sus experiencias han sido numerosas y desde la propia pre-historia del bolchevismo, a raiz de las disidencias producidas en las Primeras y Segundas Internacionales, se vienen acumulando por los doctrinarios todas las enseñanzas, hasta convertir las más provechosas en normas de acción, que han llegado a nuestros tiempos como puntos del programa subversivo a desarrollar. ",25

Estas palabras de los dirigentes de la policía política demuestran hasta qué punto le daban a los comunistas una relativa importancia ya en aquellos primeros años de posguerra. Sin embargo, en esos momentos, había muchos otros grupos activos en todo el país: republicanos, anarquistas, socialistas, poumistas, a los que la BPS también dedica su atención en los Boletines de Investigación Social (BIS), que empezarán a salir a la luz en diciembre de 1946, con el precedente de los BIA. Estos documentos ya no son tan ideológicos como los BIA, sino que se dedican más a analizar la situación del país, la cuestión del orden público, a los diferentes grupos de oposición y las diferentes detenciones realizadas en el país.

Las detenciones de miembros del PCE, van disminuyendo en esos años a medida que cae su actividad: en 1946 fueron detenidas 1322 comunistas, en 1947, 2089, en

\footnotetext{
${ }^{24}$ Fernando Hernández Sánchez, Los años de plomo....op.cit., (Barcelona: ed. Crítica, 2015), pp. 29-32 y Gregorio Morán, Miseria... pp. 43-46.

${ }^{25}$ Informe de la DGS sobre actividades comunistas en Madrid. Abril 1945, sig. 858, FNFF, p. 15.
} 
1948, 619, en 1949,227, en 195072 y en 1951, 81 ${ }^{26}$. Sin embargo, a pesar de los arrestos de dirigentes y militantes, de las penurias, las torturas y la cárcel, la organización sigue manteniendo un aparato en el exterior y grupos de militantes en el interior que le permitirán reflotarse años después.

Por eso, aunque en estos años los policías declaraban en 1949 que había habido "un notable descenso de la delincuencia político-social" 27 que les hacía ser optimistas y en 1951, declaraban que "las maquinaciones clandestinas habían llegado al mínimo"28, seguían considerando a los comunistas un peligro a tener en cuenta y resaltaban que ellos eran los que realizaban la mayor actividad de oposición.

El primero de estos boletines, de dos páginas, del 16 de diciembre de 1946, que era "extremadamente confidencial" y de "circulación reservada a los funcionarios de Policía" (al igual que los BIA), ya se trataba la cuestión del "comunismo", sobre como desde el exilio se estaba mandando a personas al interior para llevar a cabo "la agitación subversiva". De cómo se van constituyendo los comités regionales y se crean estaciones de radio en Gijón, Sevilla y Madrid ${ }^{29}$.

Cuatro días después, el 20 de diciembre, se publicó otro nuevo Boletín, donde se volvió a analizar a los comunistas, en el que explicaron como estos intentaban acaparar la atención de los “descontentos con el Régimen” y de la creación de un "Movimiento de Resistencia Clandestino", controlado por los "agitadores comunistas". Se señaló que en Huesca, la policía había desarticulado a un grupo. Que había que vigilar toda la actividad de los "huidos" en el monte, para que no llegara a sus manos propaganda clandestina ${ }^{30}$.

\footnotetext{
${ }^{26}$ DGS, Comisaría de Investigación Social, Boletín Informativo, "La actividad político-social clandestina durante 1951" AHN, p. 17. Estos boletines de información social los he encontrado en el Archivo Histórico Nacional y en el blog https://justiciaydictadura.com/ del investigador Juan José del Águila.

27 DGS, Comisaría General de Investigación Social, Boletín Informativo, "La Agitación clandestina durante el año 1949" Enero de 1950, p1., en AHN y en https://justiciaydictadura.wordpress.com/2017/04/18/relacion-provisional-de-los-boletines-informativosde-la-brigada-politico-social-bps-que-actualmente-estan-en-el-archivo-privado-de-juan-jose-del-aguila/

28 DGS, Comisaría General de Investigación Social, Boletín Informativo "La agitación clandestina durante el año 1950" FC-Mํ-Interior-Policia-H,Exp. 53081, AHN, pp. 1-2

29 DGS, Comisaría General de Investigación Social, Boletín Informativo, nº1, 16 de diciembre de 1946, "Comunismo", "Anarco-sindicalismo", pp. $1-2$ en https://justiciaydictadura.wordpress.com/2017/04/18/relacion-provisional-de-los-boletines-informativosde-la-brigada-politico-social-bps-que-actualmente-estan-en-el-archivo-privado-de-juan-jose-del-aguila/

${ }^{30}$ DGS, Comisaría General de Investigación Social, Boletín Informativo "Socialismo" y "Comunismo", n², 20/12/1946, pp. 1-2 en https://justiciaydictadura.wordpress.com/2017/04/18/relacion-provisional-de-
} 
En 1947 se fueron ya regularizando los boletines, en estos primeros tiempos, de manera semanal. Aunque se siguió mencionando a los grupos anarquistas, socialistas, poumistas, republicanos, gran parte del contenido de los informes se refieren a los comunistas. Uno de estos primeros informes data del 3 de febrero de 1947 sobre "Actividades Comunistas" donde se trata el trabajo clandestino que hacen estos grupos, de una "férrea disciplina" y con "consignas del exterior de España". La preparación para la clandestinidad era: tener un nombre que no era el suyo, un "nombre de guerra"(o como lo describe la policía, un "nombre ilegal”), se debían tener los contactos más escuetos posibles, para que en las caídas haya el menor de detenidos posible. Que a la hora de las reuniones había que tener una coartada por si eran descubiertos. Que había que llevar siempre a cabo una "vigilancia revolucionaria", que debía ser llevada sobre todo por los cuadros de la $\operatorname{organización}^{31}$.

Los policías se dedicaron a analizar y a investigar prácticamente todas las cuestiones relacionadas con los comunistas en esos años. Como su trabajo sindical, el intento de reconstruir la UGT, para conseguir una "ligazón a las masas". Muchos de los trabajadores que durante los años de la II República, militaron en el movimiento obrero lo hicieron en esta central sindical, lo que sería más sencillo para construir sus organizaciones políticas, ya que en la memoria pervivía el recuerdo de dicha organización ${ }^{32}$. También las supuestas "Escuelas especiales" que los comunistas realizaban a sus cuadros dirigentes en el exilio, para saber trabajar en la clandestinidad, para profundizar en la teoría, incluso para saber manejar explosivos. Después, en el boletín, la Policía realiza una diseminación de cómo se organizan las JSU, que tenían un secretario general, un secretario de organización y otro de propaganda, y estaban organizados en federaciones en 13 regiones del país ${ }^{33}$.

También se dedicaron a analizar a todos los "agitadores extranjeros" comunistas que llegan a nuestro país, mandados según la DGS, por la Policía

los-boletines-informativos-de-la-brigada-politico-social-bps-que-actualmente-estan-en-el-archivoprivado-de-juan-jose-del-aguila/

${ }^{31}$ DGS, Comisaría General Político-Social, Boletín informativo "Actividades comunistas", nº 3 /02/1947 AHN, pp. 1-2.

${ }^{32}$ Comisaría General Político-Social. Boletín Informativo. "Las cuestiones sindicales en las actividades de los comunistas", $\mathrm{N}^{\circ} 10,23 / 02 / 1947$, AHN, p.1.

${ }^{33}$ Comisaría General Político-Social. Boletín Informativo. "Las escuelas especiales”, No14, 26/04/1947, AHN, pp. 1-3. 
Soviética. Llegaron a describir a 3 de ellos, llamados Stolini, Maineri y de Lupi por el color de sus ojos, de su pelo, estatura y sus vestimentas ${ }^{34}$. Estuvieron estudiando también como los comunistas trataban la cuestión de la "Propaganda y Documentos", de cómo es una de sus cuestiones más principales. De cómo evitaban tener en sus casas notas que les puedan comprometer a ellos y sus compañeros. Que se aprendían bien los documentos para luego deshacerse de ellos. Que si debían guardar algún papel, lo hicieran en algún lugar seguro ${ }^{35}$. Muchas de estas informaciones las conseguían mediante las diligencias policiales, en los registros o con los chivatazos.

La policía, al igual que el regimen franquista, seguía con la imagen del PCE y de los comunistas como unos simples títeres de Moscú, cuando, como han demostrado diversas investigaciones y hemos explicado anteriormente, las relaciones eran más complejas entre los comunistas españoles y la Komintern. En 1948, mientras La Pasionaria y Santiago Carrillo, se reunion con los máximos dirigenetes de la URSS para analizar la política española, Líster pedía ayuda a Tito en Yugoslavia para seguir la lucha guerrillera, en el que momento en que se habrían grietas en las relaciones entre las repúblicas soviética y yugoslava ${ }^{36}$.

\section{LOS BOLETINES POLICIALES Y EL PCE A FINALES DE LOS 50 Y LA DÉCADA DE LOS 60}

Tras el fracaso de la lucha armada, de la entrada del régimen franquista en las instituciones políticas internacionales, favorecida por el contexto de la Guerra Fría, el PCE decide virar su táctica y estrategia hacia la lucha de masas, el "entrismo" en las organizaciones de la dictadura del movimiento obrero y estudiantil. Con los sucesos estudiantiles en febrero de 1956 en Madrid, las huelgas obreras en Asturias, Cataluña y País Vasco entre 1957 y 1959, la policía política tendrá que cambiar su forma de actuar

\footnotetext{
${ }^{34}$ Comisaría General Político-Social. Boletín Informativo. "Sobre llegada de agitadores a España", N²6, 16/12/1947AHN, p.1.

35 Comisaría General Político-Social. Boletín Informativo. Tácticas de la clandestinidad comunista", No31, 5/04/1948."AHN, p. 1.

${ }^{36}$ David, Ruiz "De la guerrilla a la fábrica. Oposición al franquismo del Partido Comunista de España" Madrid, Espacio, Tiempo y Forma, 2000, pp. 106-107.
} 
y tendrá que detenerse más en sus análisis. Todos estos cambios provocarán que, en el Congreso de Praga del PCE celebrando en diciembre de 1959, se nombre a Santiago Carrillo secretario general del Partido y se dé el giro a la política de "reconciliación nacional", apostando por la movilización de masas con la "huelga general pacífica" y por un frente unificado con organizaciones antifranquista (incluso de derechas o ex falangistas) para derrocar a la dictadura y restablecer las libertades democráticas y mejorar las condiciones de vida de los trabajadores. En un primer momento algunas de estas ideas de lucha tuvieron resultados mediocres, pero poco a poco fueron ganando terreno. Sobre todo, en la década de los 60, con el fenómeno de Comisiones Obreras $(\mathrm{CCOO})^{37}$.

En estos años, en los boletines, se detendrán mucho más en aspectos políticos de las organizaciones antifranquistas, de los miembros que las componen, etc y no en sólo hacer un recuento de sus actuaciones. Aunque seguirán con su ideario anticomunista como en los años de la posguerra. Cuando se desataron los conflictos laborales en el año 1962, las autoridades franquistas declararon que los comunistas estaban infiltrados en instituciones como la Iglesia y los católicos se estaban convirtiendo en cómplices. Organizaciones como la Juventud Obrera Católica (JOC) o la Hermandad Obrera de Acción Católica (HOAC) eran tildadas en la prensa del régimen como "filocomunistas" o "paracomunistas" 38 .

En 1958 la BPS redactará uno de los primeros boletines relacionado con universitarios miembros del PCE, sobre las detenciones de los que participaron en el VI Festival de la Juventud de Moscú. La policía política española conocía con detalle dichos Festivales. En 1955, había realizado ya un documento sobre el V, que se llevo a cabo en Varsovia. Sabían que editaban propaganda y un periódico llamado Festival para anunciarlo por todo el mundo. Los nombres de las personas encargados del aparato organizativo de la cita juvenil. También las consignas de "carácter soviético" que se

\footnotetext{
${ }^{37}$ Edualdo Casanova Surroca, El partido comunista....op.cit. p. 286, Francisco, Erice Sebares, Militancia clandestina y represión. La dictadura franquista contra la subversión comunista (1956-1963) (Gijón: ed. Trea, 2017), pp. 36-39; Carmen Molinero y Pére Ysás, De la hegemonía a la autodestrucción. El Partido Comunista de España (1956-1982), (Barcelona: ed. Crítica, 2017), pp. 18-20; Emmanuelle Treglia, "El PCE y la huelga general", Espacio, Tiempo y Forma, Serie V, Historia Contemporánea, 2008, pp. 250251.

${ }^{38}$ Miguel Ángel Giménez Martínez, "El corpus ideológico....", opc.it. p. 23 y Pere Ysás, Disidencia y subversión: la lucha del régimen franquista por su supervivencia 1960-1975, (Barcelona: ed. Crítica, 2004), p. 275
} 
lanzaron en el Congreso. Lo que no aparecen son nombres de españoles que participaran en él ${ }^{39}$.

En el boletín sobre el VI Festival de la Juventud de Moscú si aparecen los nombres de las personas que participaron en el mismo, de los detenidos en Madrid, Zaragoza y Barcelona. No sólo eso, sino que también se sabía en qué sector de la oposición estaba cada uno, en el comité de coordinación universitaria, dentro de los sindicatos del régimen. Declaraban que ambas tramas, estaban relacionadas con el Comité Central del PCE. Que la organización universitaria tenía una gran influencia, ya que se estaban formando otros grupos de oposición estudiantiles a raíz de los acontecimientos de febrero de 1956. Que el movimiento obrero estaba utilizando "modernas técnicas" de trabajo clandestino, como el entrismo en el Sindicato Vertical. Lo que sí, como desde los inicios del régimen, la policía política seguía diciendo que las tácticas seguidas por los jóvenes y los trabajadores estaban guiadas por ideas del "sovietismo". La BPS consideraba consignas como la del salario mínimo vital” o “jornada mínima” como "soviéticas". Madrid era relacionado como el "eje de la acción comunista" ${ }^{40}$.

El seguimiento del VI Festival de la Juventud por parte de la BPS también fue bastante detallado. La policía sabía que el PCE estaba haciendo propaganda dentro del país, enviando cartas a las personas que quería captar. Esos jóvenes serían los encargados del trabajo clandestino del Partido. Los asistentes al festival pasaban primero por París. Un comité de iniciativas llevado por miembros de las juventudes comunistas, les facilitaban una tarjeta de identidad "color azul" para pasar a la zona oriental. Les obligan a adoptar nombres supuestos.Las personas que viajaban no eran conocidas por la Policía por actividades comunistas. Agasajados ya en la URRS, estaban deslumbrados bajo la consigna de "paz y amistad"-designación comunista de la “coexistencia pacífica"- Tras el final del festival, los dirigentes de las JSU pedían informes de lo ocurrido y de las impresiones de dicho festival ${ }^{41}$.

39 Boletín informativo $\mathrm{n}^{\mathrm{o}} 7475$ "Comunismo: Dispositivos internacionales y actividades diversas" División de Investigación Social, 12/11/1955, AHN, pp. 8-10.

40 DGS, Boletín Informativo "La Acción estratégica del comunismo" FC-M _Interior_Policia_H,Exp. 5309, febrero 1958,AHN, pp. 4-8.

${ }^{41}$ Ibídem. pp. 2-3. 
La BPS nunca dejaría de relacionar todo lo que hacía el PCE con la URSS y también con acciones de character "subversive", cuando, como estaban demostrando en sus Congresos y programas, el PCE apostaba por la lucha de masas y pacífica. De hecho los detenidos de 1958 lo fueron por organizar la Huelga General Pacífica. Abogaban por la reconciliación y acabar con la violencia ${ }^{42}$.

A partir de la década de los sesenta, la policía centrara sus objetivos de análisis y detención, no sólo en los comunistas, sino también en nuevos grupos de oposición que van surgiendo a calor de la movilización antifranquista. Significativo es el informe que realizaron, tras una reunión de policías de todo el país expertos en movimiento estudiantil los días 7 y 8 de septiembre de 1965, donde analizaron los "problemas estudiantiles" en todos los distritos universitarios. En dicho boletín, consideraban a la Federación Universitaria de Estudiantes (FUDE), dirigida por el PCE, "la piel de cordero que encubría al comunismo" o "el disfraz del comunismo en estos medios sociales". Aunque había "estudiantes demócratas" como los mismos policías reconocían, dijeron que eran títeres de los comunistas. Para los miembros de la BPS, eran la principal organización dentro del estudiantado ${ }^{43}$.

Prácticamente cada año, siempre había un boletín de la policía política donde se analizaba la actividad de los comunistas, la procedencia de los detenidos, el trabajo realizado dentro del movimiento obrero y estudiantil. En 1961, al policía declaraba que sus intervenciones "se centraban casi exclusivamente en las de carácter comunista", de los cuales consideraba que su único objetivo era "la subversión social" ". Esta idea se verá reflejada en los siguientes boletines en los que se habla sobre el PCE.

En ese mismo año 1961, en el informe sobre las detenciones de comunistas en Madrid y Barcelona en los meses de abril y marzo, se dice que la campaña pro-amnistía

\footnotetext{
${ }^{42}$ David, Ruiz "De la guerrilla....." op.cit. pp. 119-120.

${ }^{43}$ DGS "Informe sobre las reuniones de funcionarios del Cuerpo General de Policía, afectos al servicio de información y de investigación social, de plantillas correspondientes a distritos universitarios y con derivaciones en ellos, celebradas los días 7 y 8 de septiembre 1965, sobre los problemas estudiantiles del curso 1965-66", fc-m_interior_policia_h,exp.53109_133, AHN, y FNFF, pp. 4-5 y Miguel, Gómez Oliver, "El Movimiento Estudiantil español durante el franquismo (1965-1975)" Revista Crítica de Ciencias Sociais, 81, Junio 2008, pp. 94-97.

${ }^{44}$ DGS, Boletín Informativo "Los servicios policiales en el orden político-social durante 1961”, n³49, p. 2 en https://justiciaydictadura.wordpress.com/2017/04/18/relacion-provisional-de-los-boletinesinformativos-de-la-brigada-politico-social-bps-que-actualmente-estan-en-el-archivo-privado-de-juan-josedel-aguila/
} 
que estaban llevando a cabo los comunistas iba "contra España y contra el régimen." 45 En el boletín sobre los servicios policiales realizados en 1962, año en el que se producen las huelgas en la minería asturiana que se extenderán por 28 provincias españolas en la primavera de ese año, en la que participaran 300000 trabajadores $^{46}$, los policías declararon que se "evidenció" la táctica del PCE para "implantar en España el programa de la subversión" $"$.

En 1963 le dedicarán un boletín exclusivamente a un dirigente comunista, Julián Grimau, miembro del Comité Central que fue mandado por el Partido para reorganizar el trabajo en el interior y detenido el 8 de noviembre 1962 en Madrid. Dicho documento, que se escribió tras los interrogatorios y torturas que sufrió en la DGS, se realizó para contrarrestar la campaña internacional que estaba llevando a cabo el PCE contra la detención de Grimau y las torturas que había sufrido.

La policía, en el informe, dijo que su caída por la ventana del despacho policial había sido "un intento de fuga". En el informe policial, la BPS declare que Grimau había firmado una declaración en la que confesó haber tenido "una actuación destacada en la policía roja, en la detención de personas de las organizaciones nacionales" cuando trabajaba en la Dirección General de Seguridad de Barcelona durante la Guerra Civil, y por lo que después sería juzgado y fusilado el 20 de abril de 1963. También declaró que el Partido lo había escogido como dirigente por "la experiencia en el Servicio de Información del Estado Mayor Rojo" "48.

Sobre la cuestión de las torturas y el supuesto intento de fuga o suicidio de Grimau que se defendía en el informe policial, según los informes médicos y también los investigadores, para "suicidarse, necesitaba fuerzas, carecer de vigilancia y unas ventanas limpias de obstáculos", condiciones que obviamente no se daban.Sin embargo, la versión del suicidio, fue defendida, entre otros, por Manuel Fraga Iribarne, ministro

\footnotetext{
45 DGS, Boletín informativo "La acción comunista en Madrid y Barcelona", 29/05/1961, AHN, p. 1.

${ }^{46}$ Irene Díaz y Rubén Vega "El ciclo de las grandes huelgas mineras (1957-1964) en Vega García, Rubén (coord.) El movimiento obrero en Asturias durante el franquismo 1937-1977. Ediciones KRK, Fundación Juan Muñiz Zapico, Oviedo, 2013, pp. 281-282.

47 DGS, Boletín Informativo "Los servicios policiales en el orden político-social durante 1962", 2/01/1963, p. 3 en https://justiciaydictadura.wordpress.com/2017/04/18/relacion-provisional-de-losboletines-informativos-de-la-brigada-politico-social-bps-que-actualmente-estan-en-el-archivo-privado-dejuan-jose-del-aguila/

48 DGS Comisaría General de Investigación Social. “Julián Grimau. Miembro del Comité Central del Partido Comunista” exp.53103_556, AHN, p.2-8
} 
de Información y Turismo en aquellos momentos.Los comunistas no se creían dicha versión, haciendo una campaña para que se esclarecieran los hechos y contra la tortura. Según el PCE, el caso Grimau evidenciaba lo que era el franquismo "represión, terror y tortura". Para el investigador Juan José del Águila, todas las irregularidades en el caso convierten el fusilamiento de Julián Grimau en un "crimen de estado",49

Además en los boletines de aquellos años se comenzará a analizar el fenómeno de las Comisiones Obreras, que la policía en todo momento relaciona con el PCE. Que en un principio se burlaban de estos sindicalistas llamándolo "fantasmas de Comisiones" porque la comisión desaparecía cuando acababa el conflicto. Pero luego, a mediados de los 60 y la consolidación de las CCOO en los centros de trabajo de forma permanente sí que se convertirán en una preocupación policial real. ${ }^{50}$.

Sobre todo se irá analizando tras la ilegalización de esta organización por parte del Tribunal Supremo en 1967. En un boletín de mayo de 1966, tras las detención de varios miembros del PCE en Madrid, se habla de su actividad como CCOO, en las que los comunistas tenían interés en construir, y aunque "permitían su entrada a todo el personal", según la BPS, los comunistas tenían todo el cuidado posible para controlarlas y orientarlas y llevar a cabo un trabajo legal. ${ }^{51}$. En un informe de abril de 1967, tras su ilegalización, los policías hablan de este nuevo movimiento obrero como una organización sindical que se organiza "al margen de las estructuras sindicales legales", llevando a cabo "una actividad subversiva" 52 .

Tras un periodo de análisis sobre los diferentes movimientos de oposición, la BPS se pondrá manos a la obra a seguir deteniendo y reprimiendo con contundencia. Detrás de cada movimiento veían casi siempre al PCE. De hecho, durante el estado de excepción de enero de 1969, en el informe realizado sobre las detenciones declararon

49S.N. “¡Uníos todos para que Julián Grimau sea el último española torturado!”, Mundo Obrero, diciembre 1962, p. 2 y Juan José, del Águila El Tribunal de Orden Público.....pp. 150-155.

50 Alberto Sabio Alcutén, Peligrosos demócratas: antifranquistas vistos por la policía política (19581977) Barcelona ed. Cátedra, 2011, pp. 63-64.

${ }^{51}$ DGS, Comisaría General de Investigación Social, Boletín Informativo, "Desarticulación de actividades comunistas en Madrid", 26/05/1966, $\mathrm{n}^{\circ} 6 . \quad 431, \quad$ p. $\quad 5 \quad$ en https://justiciaydictadura.wordpress.com/2017/04/18/relacion-provisional-de-los-boletines-informativosde-la-brigada-politico-social-bps-que-actualmente-estan-en-el-archivo-privado-de-juan-jose-del-aguila/

52 DGS. Comisaría General de Investigación Social. Las Comisiones Obreras ante la Ley. Boletín Informativo, 8/04/1967, p.7 en https://justiciaydictadura.wordpress.com/2017/04/18/relacion-provisionalde-los-boletines-informativos-de-la-brigada-politico-social-bps-que-actualmente-estan-en-el-archivoprivado-de-juan-jose-del-aguila/ 
que la mayoría de obreros y estudiantes que habían participado en las movilizaciones y huelgas, siembra de propaganda, tenían “inspiración y dirección del Partido Comunista”. Sin embargo, obviaban las demás organizaciones que estaban creciendo a su izquierda: maoístas, trotkistas, marxistas-leninsitas, y que estaban consiguiendo hacerse un hueco, sobre todo, en el mundo estudiantil ${ }^{53}$.

\section{EL PCE EN LOS BOLETINES DE INVESTIGACIÓN SOCIAL DE LOS ÚLTIMOS AÑOS DEL FRANQUISMO (1970-1975)}

En los últimos años de la dictadura franquista, habrá otras muchas organizaciones antifranquistas que serán objetivo de Boletines por parte de la BPS, que estaban a la izquierda de los comunistas o que practicaban la lucha armada, como el caso de ETA. Sin embargo, el PCE, que en esos momentos ya era considerado "el partido del antifranquismo" ensanchará su campo de actuación, con las comisiones de barrio, su trabajo de entrismo dentro de los Colegios de Abogados, sus alianzas con intelectuales, el asociacionismo vecinal, la creación del Movimiento Democrático de Mujeres y las victorias de candidaturas de oposición democrática en las elecciones sindicales $^{54}$.

A partir de ese momento, la política de "reconciliación nacional" se materializó en tres frentes: el conocido como "Pacto para la Libertad", que lo que establecía era la unidad entre diferentes fuerzas "de izquierda y derecha" para derrocar el Régimen, la conocida como "Alianza de las fuerzas del trabajo y la cultura", donde el PCE buscará la unidad entre trabajadores e intelectuales para crear una organización que aglutinara diversas sensibilidades sociales. El punto culmen será la instauración de la Junta

\footnotetext{
53 DGS Boletín extraordinario del Comisaría General de Investigación Social. "Estado de excepción, Madrid", 24/04/1969. Legajo 21.069, AHN, $\quad$ p. $444 \quad$ y https://justiciaydictadura.wordpress.com/2017/04/18/relacion-provisional-de-los-boletines-informativosde-la-brigada-politico-social-bps-que-actualmente-estan-en-el-archivo-privado-de-juan-jose-del-aguila/ y Pere Ysás, Disidencia y subversión.... pp. 120-123.

${ }^{54}$ Alberto Carrilos-Linares, "Movimiento estudiantil antifranquista, cultura política y transición política a la democracia", Pasado y memoria: Revista de historia contemporánea, 2006, Ejemplar dedicado a: España en los años 60; Xavier Domenech Sampere, Clase obrera, antifranquismo y cambio político, (Madrid:ed. Catarata, 2008), pp. 180-181 y Teresa María Ortega López, "Obreros y Vecinos en el tardofranquismo y la Transición Política (1966-1977). Una 'lucha' conjunta para un mismo fin”. Espacio, Tiempo y Forma, Serie V, Historia Contemporánea, nº16, 2004, pp. 362-363.
} 
Democrática, el 29 de julio de 1974 en París, dirigida por el PCE y en la que estaban otras organizaciones y personalidades antifranquistas ${ }^{55}$.

Ante esta situación, el aparato de Estado franquista, con la policía política a la cabeza, intentará desprestigiar a los comunistas, vinculándolos a los atentados terroristas de aquellos años y a organizaciones como ETA. El caso más famoso fue el intento de inculpación en el atentado de la Calle del Correro, el 13 de septiembre de 1974, donde murieron 13 personas y 40 fueron heridas que estaba en la cafetería Rolando, donde se puso el explosivo. De los detenidos por participar en el atentado estaba Eva Fortest, antigua militante del PCE. Tras las detenciones, el 24 de septiembre, el periódico $A B C$ publicó en un reportaje las fotografías de los detenidos con el título "ETA y Partido Comunista" 56.

Dos días después, esta noticia era portada del periódico, con el titular "Indignación popular contra la ETA y los comunistas"57. El 28 de septiembre, José Sainz, jefe de la BPS en Madrid, en declaraciones a los medios sobre las investigaciones del atentado, manifestó que había una estrecha relación entre ETA y el PCE, asegurando que Eva Forest y Antonio Durán eran los elementos más destacados de esta alianza. Acabó declarando: "no sé qué dirá don Santiago Carrillo. Ni nosotros decimos que a nivel de organización o comité ejecutivo o central estén implicados la ETA o el partido comunista. Lo que no cabe duda es que miembros de ETA y del partido comunista han colaborado en él." ${ }^{58}$ En su autobiografía, sin embargo, Sainz no relacionó al PCE con el atentado, aunque sí dijo que algunos comunistas fueron detenidos ${ }^{59}$.

En estos años, los boletines policiales como ya había pasado con Grimau, se centraron ya no sólo en la organización comunista en general, sino también en dirigentes y militantes que detenían. El 9 de marzo se publica un informe sobre

\footnotetext{
${ }^{55} J u n t a$ Democrática "Declaración de la Junta Democrática de España” 29 /07/1974 en http://biblioteca.andalucia.ccoo.es:8080/intranet-tmpl/prog/local repository/documents/14670 6414.pdf . Carmen Molinero, "Una gran apuesta: la oposición política a través de la movilización social” en Manuel Bueno Lluch y Sergio Gálvez Biesca, Nosotros, los comunistas. Memoria, identidad e historia social. (Madrid: Fundación de Investigaciones Marxistas, 2009), pp. 275-278 y Gregorio Morán, Miseria... op.cit., pp. 865-873. Carmen Molinero y Pére Ysás, De la hegemonía ..... op.cit, pp. 118-120

${ }^{56}$ S.N. "ETA y Partido Comunista" $A B C, 24 / 09 / 1974$, p. 12

${ }^{57}$ S.N. "Indignación popular contra ETA y los comunistas" $A B C, 26 / 09 / 1974$, p.1

${ }^{58}$ S.N. "Un hombre y una mujer ejecutaron el atentado de la calle del Correo", $A B C, 28 / 09 / 1974$, p. 31.

59 José, Sainz González, Testimonios de un policía español. Bilbao,Autoedición, 1993, pp. 366-367.
} 
Victoriano Díaz Cardiel, considerado por la BPS como "un importante miembro" del PCE. ${ }^{60}$. De familia comunista, su padre estuvo en el Ejército republicano durante la Guerra Civil. Tras el conflicto, estuvo preso y fue condenado a muerte, pena conmutada por 30 años de pena. A los 15 años, comienza a trabajar en Euskalduna y se organiza en el PCE. En 1962 dirigió las primeras huelgas en la fábrica y se convierte en uno de los dirigentes del PCE vinculados al movimiento obrero. A finales de años entra en contacto con Julián Grimau, antes de que fuera detenido. A partir de ese momento se encargaría de llevar a cabo los contactos entre el comité provincial del PCE de Madrid y los líderes comunistas dentro del movimiento obrero, como Marcelino Camacho o Julián Ariza. El 4 abril de 1965 sufre su primera detención. Años después contó las torturas que sufrió en esos días, donde los policías le rodearon y le golpearon hasta perder el sentido y le daban patadas en las esposas para que sangrara ${ }^{61}$.

El boletín en el que hablaba de su trayectoria como militante y dirigente comunista, está relacionado con la detención que sufrió el 10 de diciembre de 1973, durante las jornadas de lucha contra el proceso 1001, contra los dirigentes de CCOO. La BPS sabía que estaban deteniendo a un importante dirigente, como dejaron claro en el informe policial. La información la habían conseguido mediante el interrogatorio y el registro de su domicilio. Según la policía, los papeles eran sobre la cuestión del sumario del 1001. En su casa habían encontrado "libros y propaganda de carácter marxista”. Se hace un repaso a su historial y antecedentes. Que cuando volvió a España, se integró en las tareas del PCE, siendo captados por Julián Grimau y Luis Antonio Gil López. La BPS dijo que Grimau le había dado 17000 pesetas para la entrada de un piso. Que estuvo en Francia en reuniones sobre "oposición sindical”, donde se trataban temas relacionados con las $\mathrm{CCOO}^{62}$.

${ }^{60}$ DGS. Comisaría de Investigación Social. "Madrid. Partido Comunista de España." 9/03/1974, en https://justiciaydictadura.wordpress.com/2017/04/18/relacion-provisional-de-los-boletines-informativosde-la-brigada-politico-social-bps-que-actualmente-estan-en-el-archivo-privado-de-juan-jose-del-aguila/ p.2.

${ }^{61}$ Fernando Jauregui y Pedro Vega, Crónica del antifranquismo (Barcelona: ed. Planeta, 2007), pp. 857859. Antonio Jiménez Barca y Pablo Ordaz Así fue la dictadura. Diez testimonios de la represión franquista. (Madrid: ed. Debate, 2018), p. 83-90.

${ }^{62}$ DGS. Comisaría de Investigación Social. "Madrid. Partido Comunista de España." 9/03/1974, en https://justiciaydictadura.wordpress.com/2017/04/18/relacion-provisional-de-los-boletines-informativosde-la-brigada-politico-social-bps-que-actualmente-estan-en-el-archivo-privado-de-juan-jose-del-aguila/ p.2-3 
Además de Díaz-Cardiel se habló de otras personas a las que la BPS interrogó, ya que eran cercanas a él. Estos fueron Alberto Yébenes Simón, traductor, que según la policía, era un "sujeto de acusada significación e importancia en actividades comunistas". Trabajó de forma clandestina por el Partido en España hasta 1965, cuando se marchó a Francia. Volvió al país en 1970, cuando fue detenido y puesto a disposición judicial. Los otros interrogados fueron Juan José del Águila y Maria Luisa Roldán, abogados del PCE y para los que Díaz Cardiel trabajó como contable. Del primero se dice que en junio de 1961 fue un destacado promotor de una "alteración del orden público" y de un boicot a la propietaria de los cines de Algeciras en protesta por el precio de las localidades. La BPS lo acusó también que durante el entierro del obrero Pedro Patiño (asesinado por la Guardia Civil) en Getafe, el 16 de septiembre de 1971, creó un "ambiente para que surgiera algún incidente". Por toda esta militancia, a Juan José del Águila le retiraron el pasaporte, le expulsaron de la Universidad Central de Madrid, fue detenido y juzgado en $1968^{63}$.

Los abogados jugaron un papel fundamental de vanguardia y movilización entre los profesionales liberales. Desde finales de los años 50, jóvenes universitarios vinculados al PCE, fundan los primeros despachos laboralistas y comienzan a participar en juicios contra militante antifranquista, sobre todo con el TOP, en 1963. Estos abogados antifranquistas, entre ellos, muchas mujeres (Paca Sauquillo, Manuela Carmena, Cristina Almeida, la propia María Luisa Suárez Roldán), empezaron a ocupar puestos como representantes en los Colegios de Abogados, sobre todo, en los de Madrid o Barcelona. El culmen de su actividad llegó en 1970 con el Congreso de la Abogacía de León, donde se aprobó una declaración en apoyo a la amnistía de los presos, la supresión de las jurisdicciones especiales, la derogación de la ley de rebelión militar, bandidaje y terrorismo y la abolición de la pena de muerte ${ }^{64}$.

En esos años, muchos abogados tendrán que pasar por la represión por parte de la BPS. El 11 de noviembre de 1959, sería detenido durante 6 días, el abogado laboralista y miembro del PCE Manolo López. Estuvo detenido durante 6 días en la

\footnotetext{
${ }^{63}$ Ibidem. pp. 3-5 y https://justiciaydictadura.com/sobre-juanjo-del-aguila/

${ }^{64}$ José Alén, Claudia Cabrero, Irene Díaz y Rubén Vega, Abogados contra el franquismo (Barcelona: ed. Crítica, 2013, pp. 77-101; Pere, Ysás Disidencia y subversión.... op.cit, pp. 70-71 y Juan José del Águila "Las abogadas defensoras ante el TOP" en Ángeles Egido León y Jorge Montes Salguero Mujer, franquismo y represión una deuda histórica (Madrid: ed. Sanz y Torres, 2018), pp. 349-352
} 
DGS. En ese periodo, fue interrogado, entre otros, por Saturnino Yagüe. Desde 1964 hasta 1976, serán 45 los abogados antifranquistas juzgados por el TOP donde gran parte eran del PSUC/PCE y CCOO (17) ${ }^{65}$.

La BPS no dejaría en ningún momento de vigilar la actividad dentro de los despachos de abogados. El 6 de agosto de 1975 se publicó un boletín específico donde se habla prácticamente sólo de la actividad opositora de los abogados. En él se trata una "reunión ilegal" de letrados relacionados con el PCE en el despacho de abogados laboralistas de la Calle Atocha 49. Desde mayo de ese año habían detectado actividades de un grupo de abogados que, "siguiendo las directrices del Partido Comunista", tenían el propósito de llevar a cabo una "campaña de perturbación a escala nacional encubierto en lo llamado como Acción Democrática". Como resultado de las investigaciones descubrieron la reunión que se iba a celebrar el 15 de mayo en el despacho de Atocha. El despacho pertenecía a los abogados Manuela Carmena Castrillo y Sebastián Carlos Del Río Todera. En dicha reunión, según la BPS, se iba a discutir las directrices del PCE sobre las acciones a llevar y también la influencia de aquellos despachos laboralistas en los obreros y presionarles para "que siguieron las consignas del PCE y CCOO"66.

La BPS estableció un dispositivo de observación de la reunión. Vieron que a partir de las 16 horas entraron diversas personas, más de 20. Que como no se tenía el permiso gubernativo para celebrar dicha reunión, pidieron una orden al juzgado de Instrucción de Guardia para poder entrar, ya que se trataba, de una "reunión ilegal". Entraron con un secretario judicial y fueron detenidas 26 personas. Según la policía, los asistentes a la reunión dieron versiones contradictorias sobre los motivos de la misma, ocultando "vinculación alguna con el PCE". Nadie dijo quién les había convocado. Unos pocos se negaron a contestar a cualquier pregunta mientras no hubiera una autoridad judicial. Según algunos de los participantes en aquellas reuniones, tanto la policía como la extrema derecha les amedretaban. Los letrados se enfrentaron a estas represalias, mediante escritos contra la represión como el del

\footnotetext{
${ }^{65}$ José Alén, Claudia Cabrero, Irene Díaz y Rubén Vega, Abogados contra..... op.cit. pp. $128-137$ y Manolo López, Mañana a las once en la Plaza de la Cebada. (Madrid: editorial B, 2009, pp. 421- 423

66 DGS. Comisaría de Investigación Social. Boletín Informativo 6/08/1975. "Reunión Ilegal de Abogados", p. 2-4 en https://justiciaydictadura.wordpress.com/2017/04/18/relacion-provisional-de-losboletines-informativos-de-la-brigada-politico-social-bps-que-actualmente-estan-en-el-archivo-privado-dejuan-jose-del-aguila/.
} 
Congreso de León en 1970 e incluso con una huelga de abogados ese mismo año, por la que fueron sancionados 40 abogados ${ }^{67}$.

Sobre el análisis que hace de la abogacía antifranquista en el Boletín, la policía distingue dos tipos: los de "claro matiz comunista" y los "desafectos al Régimen", en los que estarían los socialistas, los nacionalistas vascos y catalanes, cristianos de base, izquierda radical, etc. Para la BPS, como para el franquismo en general, el gran enemigo seguían siendo los comunistas. Sobre los despachos laboralistas, la BPS recalcó que eran lugares donde la propaganda y las consignas del PCE se hacían eco, dinamizando las consultas sobre cuestiones laborales con instrucciones "para alterar el orden público". Los consideraban también "verdaderos centros nerviosos y de decisión en cuanto a la política comunista del interior del país". Para los integrantes de dichos despachos, como Cristina Almeida o Alejandro Ruiz Huerta, aquellos lugares eran "espacios de libertad" donde defender a los trabajadores y acabar con la dictadura ${ }^{68}$.

Uno de los últimos informes de la BPS en los que se habla sobre el PCE es en el que se trata las movilizaciones del $1^{\circ}$ de mayo de 1975. La festividad obrera por antonomasia fue transformada por el franquismo como un ritual religioso $y$ propagandista de su ideario nacional-católico. Sin embargo, la oposición antifranquista utilizaba esta fecha para movilizar al movimiento obrero. Días antes de la celebración de dicho acontecimiento era habitual la detención de militantes

\footnotetext{
${ }^{67}$ Los detenidos fueron: Manuela Carmena Castrillo, Sebastián Carlos del Río Todera, Jose Pablo Armendi Sánchez, María Cristina Almeida Castro, Jose María Pariente Viguera, Juan José del Águila Torres, Diego Carrasco Mesdeu, Rafael Juan Company Corro, María Dolores González Ruiz, Jose Manuel López López, María Isabel Fernández Diez, María Teresa García Rodríguez, María Antonia Lozano Álvarez, Hector Maravall Gómez-Allende, Jose María Mohedano Fuertes, Jose Ignacio Montejo Uriol, Luis Ramos Pardo, Amandino Rodríguez Armada, Jaime Axel Ruiz Baudrihaye, Ignacio Maria Salorio del Moral, Jaime Sartorius, Bermúdez de Castro, Francisco Javier Sahuquillo Perez del Arco, Rafael Zorrilla Torras, Roman del Oria Fernández de Muniaín. Todos ellos eran abogados en DGS. Comisaría de Investigación Social. Boletín Informativo 6/08/1975. "Reunión Ilegal de Abogados", pp. 25 y Documentos RNE "1970, la abogacía contra el franquismo" en https://www.rtve.es/alacarta/audios/documentos-rne/documentos-rne-1970-abogacia-contra-franquismo04-09-20/5656675/.
}

68 DGS. Comisaría de Investigación Social. Boletín Informativo del 6/08/1975. "Reunión Ilegal de Abogados", pp. 2-4 en https://justiciaydictadura.wordpress.com/2017/04/18/relacion-provisional-de-losboletines-informativos-de-la-brigada-politico-social-bps-que-actualmente-estan-en-el-archivo-privado-dejuan-jose-del-aguila/ 
antifranquistas conocidos ya por la policía para que no llevaran a cabo "su campaña de subversión" 69 .

En el boletín en el que analizaron estas movilizaciones del $1^{\circ}$ de Mayo se dijo que ese año la campaña había pasado "sin pena ni gloria", entre otras circunstancias, porque el PCE en sus campañas preparatorias de "acciones democráticas" y en otras jornadas contra la carestía de la vida. Sobre el material que sacaron los comunistas, dice la Policía que solo encontraron "una declaración de su Comisión Ejecutiva trataba el $1^{\circ}$ de Mayo." Sin embargo, frente a lo que creía la Policía, en aquellos años se producirá un importante incremento en el número de militantes en difentes ámbitos (laboral, estudiantil, vicinal), que repercutirá en posteriores movilizaciones, que se irán incrementando ${ }^{70}$.

\section{LAS MUJERES DEL PCE EN LOS BOLETINES DE INVESTIGACIÓN POLICIAL}

En los boletines policiales que he podido analizar sobre los comunistas, no se habla de las organizaciones clandestinas de mujeres comunistas, aunque si se citan a mujeres comunistas.

A pesar de que no aparecieran mucho en los boletines policiales, la policía si tenía su vista puesta en las mujeres que militaban en el antifranquismo. Durante los años de posguerra, participaban en el movimiento guerrillero, dieron cobijo a la guerrilla, hacían de enlace, se agruparon en la Agrupación de Mujeres Antifascistas. Las columnas de operaciones en Asturias en 1939 declaró que "había poca colaboración ciudadana" y sobre todo, entre las mujeres ${ }^{71}$.

\footnotetext{
${ }^{69}$ José Babiano, $1^{\circ}$ de Mayo. Historia y significado. ed. Altaban, (Madrid: 2006, pp. 73-80).

70 DGS, Boletín Informativo nº 9/09/1975 “Campaña subversiva $1^{\circ}$ de Mayo", p. 5 en https://justiciaydictadura.wordpress.com/2017/04/18/relacion-provisional-de-los-boletines-informativosde-la-brigada-politico-social-bps-que-actualmente-estan-en-el-archivo-privado-de-juan-jose-del-aguila/ y Carmen Molinero, "Una gran apuesta...." op.cit., pp. 260-262.

${ }^{71}$ 1939, agosto, Columna de Operaciones de Asturias. Instrucciones para el Delegado de Orden Público.
} Sig. 26039, FNFF, p.1 
Acabada la guerrillera, se encargaron muchas mujeres de reconstruir las redes clandestinas comunistas, aunque sin posiciones de vanguardia, por las reticencias de los partidos de la oposición hacia la cuestión de la mujer. En los años 60, comenzarán a participar en las movilizaciones obreras, realizando piquetes, pidiendo la libertad de los presos politicos, participando en las asociaciones vecinales. En los 70, crearon sus propias organizaciones feministas y antifranquistas. La más importante dentró del PCE fue el Movimiento Democrática de Mujeres y la Asociación Española de Mujeres Universitarias $^{72}$.

Por todo esto, las mujeres fueron reprimidas, con castigos típicamente femeninos. Entre ellos, destacaban el rapado de pelo como marca infamante, la ingestión de aceite de ricino, constantes vejaciones públicas, las quemaduras de pechos y lo más brutal, la violación, utilizada como instrumento de humillación y sumisión. En la posguerra muchas mujeres comunistas sufrieron este tipo de represalias. Pero incluso en 1963, dos mujeres comunistas asturianas, Anita Sirgo y Tina Pérez, la Guardia Civil les raparon el pelo por participar en un piquet de las huelgas mineras ${ }^{73}$.

A pesar de toda esta movilización de las mujeres, solo he encontrado dos referencias de mujeres en los boletines que he encontrado. Es el caso de María Luisa Suárez Roldán o Manuela Carmena, ambas abogadas laboralistas. De la primera, que se hablaba de ella en el informe sobre la detención de Victoriano Díaz Cardiel, lo que se dice es que era de tendencias "contrarias al Régimen" y la conceptúan como “extremista". Que tenía antecedentes por defender a personas en el TOP. Que había varias notas policiales sobre ella relacionada con el grupo de "Abogados Jóvenes" de Madrid. Que ya desde 1960 mantenía contactos con "juristas demócratas”. En 1973, según la Policía, era presidenta de la Asociación Española de Mujeres Universitarias y

\footnotetext{
${ }^{72}$ Claudia Cabrero Blanco, Mujeres contra el franquismo (Asturias 1937-1952). (Oviedo: KRK, 2006), pp. 283-310; Francisco Erice Sebares, "Mujeres comunistas: la militancia femenina en el comunismo asturiano, de los orígenes al final del franquismo" en Francisco Erice Sebares (ed.) Los comunistas en Asturias 1920-1982, (Oviedo: ed. Trea 1996), pp. 331-335 y Francisco Arriero Ranz, El movimiento democrático de mujeres: de la lucha contra Franco al feminismo (1.965-1985) (Madrid: ed. catarata, 2016), pp. 211-213; Gloria Nielfa Cristobal, ”Trabajo, legislación y género en la España contemporánea: los orígenes de la legislación laboral”en Lina Gálvez-Muñoz y Carmen Sarasúa, (coord.) ¿Privilegios o eficiencia?: Mujeres y hombres en los mercados de trabajo, (Universidad de Alicante, 2003), pp. 12-15.

73 Ángeles Egido León "Ser roja y ser mujer: condicionantes y desencadenantes de la represión de género" en Ângeles Egido León y Jorge Montes Salguero Mujer, franquismo....pp. 15-18; Enrique González Duro, Las rapadas. El franquismo contra la mujer. (Madrid: Ed. Siglo XXI), 2012, pp. 20-25 y Claudia Cabrero Blanco, "Militancia, resistencia y solidaridad. Las mujeres comunistas y la lucha clandestina del primer franquismo" en Manuel Bueno Lluch, y Sergio Gálvez Biesca, Nosotros los comunistas.... op.cit. pp. 208-217
} 
asistente a la Plataforma Democrática. Que había asistido a reuniones extraordinarias en el Colegio de Abogados de Madrid. Fue una de las impulsoras del primer despacho laboralista abierto en Madrid, en la calle Cruz $\mathrm{n}^{\circ} 16{ }^{74}$. Sin embargo, de la segunda, que se la cita en el informe sobre la reunión ilegal de abogados, lo único que se dice es que hija de Carmelo y Matilde, que vivía en Calle Lira, que era abogada y estaba casa. Que al registrarla se le encontró una fotocopia del Manifiesto por la reconciliación nacional de la Junta Democrática. También se dice que el despacho donde se reunían era suyo ${ }^{75}$.

\section{CONCLUSIONES}

Desde los años 80, tras el paso de la dictadura a la democracia, el PCE abrió su archivo a la ciudadanía, para que se conociera la aportación de la lucha de los comunistas en la consecución para conseguir las libertades y derechos sociales, desde los inicios hasta el final de la dictadura. Primero con las armas en la mano en los montes y después, colaborando con las organizaciones y desarrollo de movimientos de masas contra el régimen franquista. Y que no se olvidará tampoco la represión que sufrieron los comunistas. ${ }^{76}$.

Para el franquismo, el comunismo era uno de los principales "enemigos" a batir. El anticomunismo, junto con otros ideales como el antiliberalismo o el catolicismo, será uno de las ideas viscerales desde el principio hasta el final del régimen. Se vinculaba a los comunistas españoles con "la conspiración comunista mundial" dirigida por la URSS, e identificando al PCE con la Guerra Civil y hechos dramáticos como la matanza de Paracuellos, como estrategia de "infiltración" del comunismo. Sin embargo, la

\footnotetext{
74 DGS. Comisaría de Investigación Social. "Madrid. Partido Comunista de España." 9/03/1974, en https://justiciaydictadura.wordpress.com/2017/04/18/relacion-provisional-de-los-boletines-informativosde-la-brigada-politico-social-bps-que-actualmente-estan-en-el-archivo-privado-de-juan-jose-del-aguila/ pp. 5-8.

75 DGS. Comisaría de Investigación Social. Boletín Informativo del 6/08/1975. "Reunión Ilegal de Abogados", pp. 2-3 en https://justiciaydictadura.wordpress.com/2017/04/18/relacion-provisional-de-losboletines-informativos-de-la-brigada-politico-social-bps-que-actualmente-estan-en-el-archivo-privado-dejuan-jose-del-aguila/

${ }^{76}$ Victoria Ramos, "La represión franquista en el Archivo del PCE" Hispania Nova, Revista de Historia Contemporánea, $\mathrm{n}^{\mathrm{0}}$, 2007, pp. 5-6.
} 
política del PCE realmente en esos años, sobre todo a partir de 1956, se basó en una política de alianzas con todas las fuerzas sociales existentes en España, salvo con el búnker franquista ${ }^{77}$.

Esta visión del PCE por parte de Franco y su propio sistema, se reflejó en todas sus instituciones. Incluido, la policía política del régimen, que se dedicaba al análisis, estudio, detención y torturas de los militantes antifranquistas. Estas ideas las reflejaron, sobre todo, en los Boletines policiales, informes que realizaban los miembros de la BPS para examinar la actividad de la oposición y las detenciones que llevaban a cabo los propios policías. Estos documentos, que sólo podían consultar los agentes o los miembros de la DGS, son fundamentales para entender el funcionamiento de parte de las fuerzas de orden público durante la dictadura.

Muchos de estos boletines están centrados en la actividad del PCE, tanto en el interior, como en el exilio. La escritura de estos textos respecto a los comunistas la podemos dividir en cuatro etapas. En un primer momento, entre 1938 y 1945, en los Boletines de Información Anti-marxista, Comín Colomer, el escritor-policía encargado de redactar dichos documentos, se encargó de analizar, desde el punto de vista franquista, los inicios del comunismo en España, la creación de organizaciones comunistas internacionales y sus vínculos con el PCE, la historia de la URSS y de organizaciones como la GPU. Se hizo un análisis más teórico que de la actividad diaria contra los comunistas, redundando en los tópicos (la Komintern tras el PCE, el oro ruso, etc) que ya han sido rebatidos por la historiografía.

Una segunda etapa, que abarcaría desde mediados de los 40 hasta el ecuador de los 50, cuando los boletines ya reflejan las detenciones que realiza la policía. En ellos, se puede ver como los comunistas se convirtieron en el principal "rival" de la BPS, por el número de detenciones que se realizan. Aunque en esta época, tras acabar con la vieja oposición venida de la República y la Guerra Civil, y sentirse satisfecho, siguen viendo a los comunistas como un temor a tener en cuenta.

Una tercera etapa, que va desde 1956 hasta finales de los 70, en que comenzó a aparecer una nueva oposición al régimen, de jóvenes que no habían participado en la Guerra Civil, con nuevas formas de actuar (entrismo, CCOO, sindicatos estudiantiles democráticos) y el PCE se vincula a la lucha de masas. La policía analizará estos

\footnotetext{
77 Miguel Ángel Giménez Martínez "El corpus ideológico....” op.cit. pp. 23-24; Enrique, González de Andrés, "La naturaleza política......" op.cit., p. 15.
} 
movimientos entre los trabajadores y estudiantes, por parte de los comunistas, combinando la reflexión teórica con las cuestiones prácticas de detenciones, vigilancia de opositores, etc. Se realizan boletines de personajes específicos, como Julián Grimau.

Una cuarta etapa, que abarcaría los últimos cinco años del régimen, donde se analizaría no sólo la actividad de los comunistas en fábricas o universidades, sino en otros sectores como los intelectuales y las profesionales liberales, como la abogacía. Se analizará de forma pormenorizada a dirigentes y militantes comunistas.

Sin embargo, a pesar de estas cuatro etapas claras de los boletines policiales del PCE hay una serie de rasgos que los une. Un anti-comunismo exacerbado, considerando a muchas organizaciones que no eran del PCE como "comunistas" o a cualquier democrática como "comunista". Una idea de las huelgas o movilizaciones como una cuestión de "subversión social" dirigida en ocasiones desde el extranjero (ya sea la URSS o los exiliados). También la escasa aparición en los boletines de las mujeres comunistas, que surgen, y de una forma muy superficial, en los últimos informes policiales, coincidiendo con la visión patriarcal del franquismo de la mujer que no debía participar en política. Esta fue un error de cálculo de los boletines de la BPS, ya que las mujeres jugaron un papel importante en la lucha contra el franquismo. Por ello, también fueron reprimidas.

\section{BIBLIOGRAFÍA}

Alén, José; Cabrero, Claudia; Díaz, Irene y Vega, Rubén. Abogados contra el franquismo. Barcelona, ed. Crítica, 2013.

Águila Torres, Juan José del. "Las abogadas defensoras ante el TOP” en Egido León, Ángeles y Montes Salguero, Jorge. Mujer, franquismo y represión una deuda histórica Madrid, ed. Sanz y Torres, 2018, pp. 349-352

-- El Tribunal de Orden Público 1963-1977, trece años de represión política (19631977), Tesis Doctoral, Universidad de Sevilla, 1997.

Arriero Ranz, Francisco. El movimiento democrático de mujeres: de la lucha contra Franco al feminismo (1.965-1985) Madrid, ed. catarata, 2016

Babiano, José. $1^{\circ}$ de Mayo. Historia y significado. ed. Altaban, Madrid, 2006.

Cabrero Blanco, Claudia. Mujeres contra el franquismo (Asturias 1937-1952). Oviedo, KRK, 2006.

-- “Asturias. Las mujeres y las huelgas" Babiano, José (ed.) Del hogar a la huelga. Trabajo, género y movimiento obrero durante el franquismo. Madrid, ed. Catarata, 2007 
Cabrero Blanco, Claudia. "Militancia, resistencia y solidaridad. Las mujeres comunistas y la lucha clandestina del primer franquismo" en Bueno Lluch, Manuel, Gálvez Biesca, Sergio, Nosotros, los comunistas. Memoria, identidad e historia social. Madrid, Fundación de Investigaciones Marxistas, 2009

Carrilos-Linares Alberto. "Movimiento estudiantil antifranquista, cultura política y transición política a la democracia."Pasado y memoria: Revista de historia contemporánea, 2006, Ejemplar dedicado a: España en los años 60, doi: https://pasadoymemoria.ua.es/article/view/2006-n5-movimiento-estudiantilantifranquista-cultura-politica-y-transicion-politica-a-la-democracia

Casanova Surroca, Edualdo. El partido comunista de España (1920-1991), Zaragoza, ed. Saberes inútiles, 2018.

Díaz Díaz, Benito. "Tiempos de violencia desigual: guerrilleros contra Franco (19391952)" Vínculos de Historia, No 5, 2016.

Díaz, Irene; Vega, Rubén. "El ciclo de las grandes huelgas mineras (1957-1964) en Vega García, Rubén, (coord.) El movimiento obrero en Asturias durante el franquismo 1937-1977. Ediciones KRK, Fundación Juan Muñiz Zapico, Oviedo.

Domenech Sampere, Xavier. Clase obrera, antifranquismo y cambio político, Madrid, ed. Catarata, 2008.

Egido León, Ángeles. "Ser roja y ser mujer: condicionantes y desencadenantes de la represión de género" en Ángeles Egido León y Jorge Montes Salguero Mujer, franquismo y represión una deuda histórica, Madrid, ed. Sanz y Torres, 2018.

Elorza, Antonio y Bizcarrondo. Marta Queridos Camaradas. La Internacional Comunista y España (1931-1939), Barcelona, ed. Planeta, 1999.

Erice Sebares, Francisco. Militancia clandestina y represión. La dictadura franquista contra la subversión comunista (1956-1963), Gijón, ed. Trea, 2017.

-- "Mujeres comunistas: la militancia femenina en el comunismo asturiano, de los orígenes al final del franquismo" en Erice Sebares, Francisco (ed.) Los comunistas en Asturias 1920-1982, Oviedo, ed. Trea 1996

Faraldo, Jose María. Las redes de terror. Las policías secretas comunistas y su legado. Madrid, Galaxia Gutenberg, 2018

García Piñeiro, Ramón. Luchadores del ocaso, Oviedo, KRK, 2015.

Giménez Martínez, Miguel Ángel. "El corpus ideológico del franquismo: principios originarios y elementos de renovación" Estudios Internacionales Instituto de Estudios Internacionales Universidad de Chile, $\mathrm{n}^{\circ} 180,2015$. Doi: https://www.uchile.cl/publicaciones/112492/estudios-internacionales-n-180

Gómez Bravo, Gutmaro. Geografía Humana de la represión franquista. Del golpe a la guerra de ocupación. 1936-1941. Madrid, ed. Cátedra, 2017.

Gómez, Gutmaro y Marco, Jorge. La obra del miedo. Violencia y sociedad en la España franquista (1936-1950), Madrid, editorial Península, 2011.

Gómez Oliver, Miguel. "El Movimiento Estudiantil español durante el franquismo (1965-1975)", Revista Crítica de Ciencias Sociais, 81, Junio 2008

González de Andrés, Enrique. "La naturaleza política de la dictadura franquista según el PCE y sus efectos en los inicios de la Transición Española” en Ibarra Aguirregabiria, Alejandra (coord.) No es país para jóvenes, Asociación Histórica Contemporánea. Actas Encuentro Jovenes Investigadores, 2012.

González Duro, Enrique. Las rapadas. El franquismo contra la mujer. Madrid, Siglo XXI Editores.

Hernández Sánchez, Fernando. Guerra o revolución. El partido comunista en la Guerra Civil. Barcelona, ed. Crítica, 2010 
-- Los años de plomo: la reconstrucción del PCE en el primer franquismo (19391953), Barcelona , ed. Crítica, 2015

-- La frontera salvaje: un frente de sombrio del combate contra Franco, Barcelona,ed. Pasado y Presente, 2018.

-- "El Partido Comunista de España en la Segunda República” Bulletin d'Histoire Contemporaine de l'Espagne. Doi: https://journals.openedition.org/bhce/684

Jauregui, Fernando y Vega, Pedro. Crónica del antifranquismo Barcelona,ed. Planeta, 2007.

Jiménez Barca, Antonio y Ordaz, Pablo. Así fue la dictadura. Diez testimonios de la represión franquista. Madrid, ed. Debate, 2018

Jiménez Herrera, Fernando. “¿Hubo checas en el madrid de la guerra civil? estudio comparado de la policía política soviética y los comités revolucionarios españoles (Verano-otoño 1936)" Hispania Nova, n¹7, 2009, pp. 74-76 https://doi.org/10.20318/hn.2019.4516

López, Manolo. Mañana a las once en la Plaza de la Cebada. Madrid, editorial B, 2009

Marco, Jorge. Guerrilleros y vecinos en armas. Identidades y culturas de la resistencia antifranquista. Granada, ed. Comares, 2012.

Mesa, Roberto. Jaraneros y alborotadores: Documentos sobre los sucesos estudiantiles de febrero de 1956 en la Universidad Complutense de Madrid, Madrid, Editorial Complutense, 1982

Molinero, Carmen; Ysás, Pére. De la hegemonía a la autodestrucción. El Partido Comunista de España (1956-1982), Barcelona, ed. Crítica, 2017

Molinero, Carmen. "Una gran apuesta: la oposición política a través de la movilización social” Bueno Lluch, Manuel, Gálvez Biesca, Sergio, Nosotros, los comunistas. Memoria, identidad e historia social. Madrid, Fundación de Investigaciones Marxistas, 2009

Morán, Gregorio. Miseria, grandeza y agonía del PCE (1939-1985), Madrid, ed. Akal, 2018 (red. De 1986)

Nielfa Cristobal,Gloria. "Trabajo, legislación y género en la España contemporánea: los orígenes de la legislación laboral" en Gálvez-Muñoz, Lina y Sarasúa, Carmen (coord.). ¿Privilegios o eficiencia?: Mujeres y hombres en los mercados de trabajo, Universidad de Alicante, 2003

Ortega López, Teresa María. "Obreros y Vecinos en el tardofranquismo y la Transición Política (1966-1977). Una 'lucha' conjunta para un mismo fin”. Espacio, Tiempo y Forma, Serie V, Historia Contemporánea, $\mathrm{n}^{\circ} 16,2004$.

Ramos, Victoria. "La represión franquista en el Archivo del PCE" Hispania Nova, Revista He Historia Contemporánea, $\mathrm{n}^{\circ} 7, \quad 2007$. http://hispanianova.rediris.es/7/dossier/07d005.pdf

Rodríguez Puertolas, Julio. Literatura fascista española, Madrid, Ed. Akal, 1986.

Ruiz. David. "De la guerrilla a la fábrica. Oposición al franquismo del Partido Comunista de España" Madrid, Espacio, Tiempo y Forma, 2000, pp. 105-124 http://revistas.uned.es/index.php/ETFV/article/view/3016

Sabio Alcutén, Alberto. Peligrosos demócratas: antifranquistas vistos por la policía política (1958-1977) Barcelona ed. Cátedra, 2011.

Sainz González, José. Testimonios de un policía español. Bilbao, Autoedición, 1993

Treglia, Emmanuelle. "El PCE y la huelga general", Madrid, Espacio, Tiempo y Forma, Serie V, Historia Contemporánea, 2008, pp. 249-263, http://revistas.uned.es/index.php/ETFV/article/view/1513 
Pablo Alcántara López

El PCE en la lupa de la Brigada Político Social. Los comunistas en los boletines policiales (1938-1975)

Ysás, Pere. Disidencia y subversión: la lucha del régimen franquista por su supervivencia 1960-1975, Barcelona, ed. Crítica, 2004. 